\title{
ASPIRE \\ THE TIME IS NOW: STRATEGIES TO ADDRESS RACISM, EQUITY, AND THE RETENTION OF BLACK FACULTY
}

THE NATIONAL ALLIANCE FOR INCLUSIVE \& DIVERSE STEM FACULTY

Kimberly A. Griffin \& Antoinette Newsome, University of Maryland

A fter decades of "pipeline" programs that focus on preparing Black faculty to navigate racist and inequitable environments, institutions must take responsibility for developing programs, policies, and structures to make progress and create change. Given the persistent underrepresentation of Black faculty relative to their population in the U.S. and student body, as well as the unique ways anti-Black racism can manifest in academic departments and programs, leaders must develop strategies specific to the needs and experiences of Black professors. This document provides guidance to institutional leaders and policymakers, highlighting well documented challenges Black faculty face and offering actions to promote equity and justice.

\section{Address Climate Issues}

Many Black faculty experience work environments that are marked by racism, microaggressions, and overall lack of institutional support or meaningful acknowledgment of the experiences they face ${ }^{1}$. Researchers highlight how being the only Black scholar or person of color in one's department or program can be isolating and marginalizing, and Black women particularly describe encounters with stereotypes about their abilities and hyper surveillance of their appearance and tone ${ }^{2}$. Additionally, colleagues and students may disrespect Black faculty, triggering a need to defend their credentials, curriculum and pedagogical choices, and research agendas ${ }^{3}$. These experiences often translate to lower rates of scholarly productivity, significant stress, disconnection from colleagues, and decisions to leave their institutions.

Supportive words from leadership that acknowledge these dynamics or express solidarity with anti-racist social movements matter, but only to the extent that they are followed by actions. All levels of leadership must be willing to engage in uncomfortable conversations and name issues of racism, sexism, and discrimination, acknowledging their prevalence and

\section{"All levels of leadership must be willing to engage in uncomfortable conversations and name issues of racism, sexism, and discrimination."} impact on their own campuses. Expanding opportunities and implementing policies that require students, staff, and faculty to learn about anti-Black racism, bias, and discrimination can signal the importance of equity and individual investment in institutional change. Additionally, institutions must hold those who are contributing to hostile climates and racist environments accountable for their actions through annual reviews and professional development plans. Finally, leaders must demonstrate transparency and accountability in their change efforts, soliciting and perhaps most importantly responding to feedback, intentionally incorporating Black professors' recommendations and needs.

\footnotetext{
${ }^{1}$ Flaherty, C. (2020, October 21). The souls of Black professors. Inside Higher Ed. Retrieved from https://www.insidehighered.com/ news/2020/10/21/scholars-talk-about-being-black-campus-2020

${ }^{2}$ Pittman, C.T. (2010). Race and gender oppression in the classroom: The experiences of women faculty of color with white male students. Teaching Sociology, 38, $183-196$.

${ }^{3}$ Griffin, K.A. (2020). Looking beyond the pipeline: Institutional barriers, strategies, and benefits to increasing the representation of women and men of color in the professoriate. In L. Perna (Ed.), Higher education: Handbook of theory and research (vol. 35). Switzerland: Springer. https://doi. org/10.1007/978-3-030-31365-4_4.
} 


\section{Recognize and Validate Black Professors' Labor}

Many Black faculty are overburdened with large teaching and advising loads, requests to represent "diversity" on committees, mentoring and supporting students of color, and addressing campuswide racism and equity issues. These are valuable and necessary contributions that sustain institutions; however, these forms of additional labor are often unpaid and unrecognized within traditional reward structures, distracting from the most highly rewarded and regarded forms of work (e.g., teaching small seminar classes with graduate students,

"Supporting BIPOC students and engaging in diversity and equity work should not be the responsibility of Black faculty alone." engagement in grant funded projects, scholarly productivity $)^{4}$. These workload dynamics have been linked to lower and slower rates of tenure and advancement for Black professors. Further, these demands can translate to burnout and negatively impact Black scholars' mental and physical health ${ }^{5}$.

Institutions must develop meaningful ways to recognize the many contributions Black faculty are making to the academy, revising policies to be more inclusive of the work they do which is so critical to student persistence and institutional transformation. Further, institutional leaders must critically evaluate policies and practices for potential biases to address the ways Black faculty labor is minimized, ignored, and disregarded. Uneven workloads can also be addressed by more significant investment in Black faculty, supporting their additional commitments with course releases and leaves, teaching assistants, and opportunities to apply for research supplements.

Institutions should also evaluate service assignments from an equity perspective. Supporting BIPOC students and engaging in diversity and equity work should not be the responsibility of Black faculty alone; institutions must develop strategies to train faculty in inclusive practices and demand broad investment in supporting marginalized and minoritized students. Investment and required engagement in mentoring training programs and resources can enhance mentors' abilities to recognize racism and honor mentees' identities, improving students' experiences and more equitably sharing the responsibility for student support ${ }^{6}$.

\section{Create Structures of Mentoring and Support}

Mentoring is often recommended as a source of support, and Black faculty often seek close relationships with senior scholars of color. While potentially beneficial, small numbers of faculty of color in the senior ranks make identity-based matches more difficult to find and sustain, and shared racial identity does not ensure effective support and guidance in all relationships ${ }^{7}$.

Rather than focusing solely on whether or not a Black professor has a mentor, leaders must address whether faculty have equal access to the benefits associated with good mentorship, such as a broader personal and professional network, sense of support and belonging,

"Rather than focusing
solely on whether or not
a Black professor has
a mentor, leaders must
address whether faculty
have equal access to the
benefits associated with
good mentorship."

"Rather than focusing solely on whether or not a Black professor has a mentor, leaders must address whether faculty benefits associated with good mentorship."

\footnotetext{
${ }^{4}$ Anthym, M., \& Tuitt, F. (2019). When the levees break: the cost of vicarious trauma, microaggressions and emotional labor for Black administrators and faculty engaging in race work at traditionally White institutions. International Journal of Qualitative Studies in Education, 32(9), $1072-1093$.

${ }^{5}$ Davis, S., \& Brown, K.J. (2017). Automatically Discounted: Using Black Feminist Theory to Critically Analyze the Experiences of Black Female Faculty. International Journal of Educational Leadership Preparation, 12(1), 1-9.

${ }^{6}$ National Research Mentoring Network (https://nrmnet.net) and the Diversity Program Consortium (https://www.diversityprogramconsortium.org/ pages/anti-racism_resources) offer outstanding resources and training programs.

${ }^{7}$ Baker, V., Pifer, M., \& Griffin, K.A. (2014). Mentor-protégé fit: Identifying and developing effective mentorship across identities in doctoral education. International Journal for Researcher Development, 5(2), 83-98.
} 
information about professional opportunities, and feedback on their work and progress. Implementing workshops that provide information about professional development, hosting grant development meetings with teams of scholars, and identifying and training senior scholars willing to provide support for small groups of faculty are innovative strategies gaining traction. Finally, leaders can and should invest in organizations that provide support and belonging for Black faculty. Affinity groups often form organically, connecting Black faculty with their colleagues across departments and programs, creating affirming spaces for connection and collaboration. In addition to supporting these organizations with financial and administrative resources, the insights these groups can offer in regards to promoting equity and justice on campus should be solicited, and both acknowledged and incorporated in organizational change efforts.

\section{Conclusion}

Institutions and departments must translate their understanding of Black faculty experiences into action to improve their visibility, retention rates, and sense of belonging. They must provide holistic support for Black faculty and directly address the inequities ingrained in policies and practices that structurally disadvantage them. University leaders must go beyond addressing the individual and transform the system by investing in long-lasting concrete changes. Taking responsibility by addressing these barriers through comprehensive strategies is the only path to true equity and inclusion.

\footnotetext{
${ }^{8}$ Griffin, K. A., Pifer, M. J., Humphrey, J. R., Hazelwood, A. M. (2011). (Re)Defining departure: Exploring Black professors' experiences with and responses to racism and racial climate. American Journal of Education, 117(4), 495-526.
}

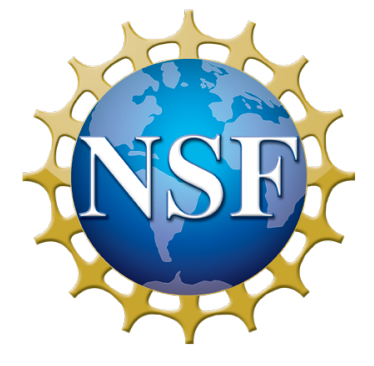

This material is based upon work supported by the National Science Foundation under Grant No. (1834518, 1834522, 1834510, 1834513, 1834526, 1834521). Any opinions, findings, and conclusions or recommendations expressed in this material are those of the authors and do not necessarily reflect the views of the National Science Foundation. 